\title{
Effect of Chlorpromazine on Blood Glucose and Plasma Insulin in Man
}

\author{
G. Erle, M. Basso, G. Federspil, N. Sicolo and C. Scandellari \\ Divisione di Malattie Metaboliche, Ospedale Civile, Vicenza, and Istituto di Semeiotica Medica, Università di Padova, Padova, Italy
}

\begin{abstract}
Summary. In three groups of normal subjects and in one group of patients with latent diabetes mellitus a study has been made of the effects of chlorpromazine (CPZ) on blood glucose and plasma insulin. CPZ 75 $\mathrm{mg} /$ day for 7 days did not alter the plasma insulin response after oral glucose; nor did CPZ $50 \mathrm{mg} /$ day for 7 days affect the glucose assimilation rate or insulin response to glucose injection. Infusion of CPZ $50 \mathrm{mg}$ in 60 min slightly increased the basal blood glucose level but had no significant effect on basal plasma insulin. The insulin/glucose ratio after the end of the infusion was significantly higher than during the period of infusion of the drug. In latent diabetic patients CPZ infusion significantly diminished the insulin/glucose ratio during an intravenous glucose tolerance test. These results suggest that, whereas prolonged treatment with low doses of CPZ did not modify glucose tolerance and glucose-stimulated pancreatic response, higher acute doses of the drug may induce hyperglycaemia and can inhibit insulin secretion both in normal man and in patients with latent diabetes mellitus.
\end{abstract}

Key words: Chlorpromazine, glucose, glucose utilization, hyperglycaemia, insulin, insulin secretion, latent diabetes mellitus.

During treatment with chlorpromazine (CPZ) a rise in blood glucose concentration has been reported (Hiles, 1956; Waitzkin, 1966; Gerich, Martin and Recant, 1971). It has recently been observed that CPZ inhibits glucose-induced insulin secretion from Langerhans' islets in vitro (Ammon and Steinke, 1971; Ammon, Orci and Steinke, 1973). Subsequently, Lambert, Henquin and Orci (1972), Federspil, Casara and
Stauffacher (1974) and Scandellari et al. (1975) reported that administration of CPZ increased the level of blood glucose and inhibited insulin secretion in hypoglycaemic patients.

At present, the effect of CPZ on insulin secretion in normal man is not fully understood. The present study was done to examine the changes in blood glucose and plasma insulin produced by acute and shortterm administration of this drug.

\section{Materials and Methods}

Four types of experiments were performed in which three groups of healthy volunteers were studied after an overnight fast.

\section{a. Experiment 1}

An oral glucose tolerance test (IVGTT) was performed in five subjects. The patients were given glucose $100 \mathrm{~g}$ dissolved in water $200 \mathrm{ml}$. Blood samples were taken from the antecubital vein before and 10 , $30,60,90,120,150$ and $180 \mathrm{~min}$ after ingestion of the glucose. The patients then took chlorpromazine 75 $\mathrm{mg} /$ day for 7 days and the study was repeated immediately after discontinuation of the treatment.

\section{b. Experiment 2}

An intravenous glucose tolerance test was performed in ten subjects. The patients were given glucose $20 \mathrm{~g}$ in $3 \mathrm{~min}$. Blood samples were taken before and 3, 10, 20, $30,35,40,45,50$ and $60 \mathrm{~min}$ after the glucose injection. Afterwards the patients were given chlorpromazine $50 \mathrm{mg} /$ day for 7 days. A second IVGTT was done immediately after discontinuation of the $\mathrm{CPZ}$ treatment. 


\section{c. Experiment 3}

Ten subjects received a CPZ infusion. The patients were recumbent during the study. Chlorpromazine $50 \mathrm{mg}$ was dissolved in saline $250 \mathrm{ml}$ and was infused over $60 \mathrm{~min}$. Blood samples were taken 15 and $0 \mathrm{~min}$ before and 30, 60, 90 and 120 min after starting the infusion.

\section{d. Experiment 4}

A first intravenous glucose tolerance test was done in 6 patients with chemical diabetes. $30 \mathrm{~min}$ before the glucose injection a saline infusion was begun which was continued until $30 \mathrm{~min}$ after the glucose administration.

A few days later a second IVGTT was done and on this occasion, $30 \mathrm{~min}$ before the glucose injection, a CPZ infusion was begun ( $50 \mathrm{mg}$ in $60 \mathrm{~min}$ ), which was continued until 30 min after the glucose administration.

Blood samples were taken before the saline or CPZ infusion, 30 and $15 \mathrm{~min}$ before the glucose injection and $3,10,20,25,30,35,40,50,60$ and $90 \mathrm{~min}$ after the glucose administration.

The plasma insulin/blood glucose ratio was calculated by dividing the plasma level of glucose $(\mathrm{mg} /$ $100 \mathrm{ml})$ by that of insulin $(\mu \mathrm{U} / \mathrm{ml})$.

Before and during the experiments all the subjects were given a mixed diet containing at least $250 \mathrm{~g}$ of carbohydrates.

Blood glucose was measured by the method of Hugget and Nixon (1957) and plasma insulin according to Herbert (1967).

\section{Statistical Methods}

In Experiments 1,2 and 3 the statistical significance of the observed results was analyzed using paired comparisons (Student's 't' test).

In Experiment 4 the insulin/glucose ratios after iv glucose were analyzed by covariance analysis.

\section{Results}

Daily administration of CPZ for 7 days in doses of 50 and $75 \mathrm{mg} /$ day did not significantly modify basal levels of blood glucose or plasma insulin. After an oral glucose load, blood glucose levels observed after short-term CPZ treatment were slightly lower than those measured under basal conditions, but the difference was not statistically significant. The plasma insulin response induced by oral glucose showed no significant change after administration of CPZ (Table 1).

After intravenous injection of glucose, the mean
Table 1. Effect of short-term CPZ treatment ( $75 \mathrm{mg} /$ day for 7 days) on blood glucose and plasma insulin in five normal subjects after oral glucose load (Mean $\pm \mathrm{SEM}$ )

\begin{tabular}{|c|c|c|c|c|c|c|c|c|}
\hline Time (min) & 0 & 10 & 30 & 60 & 90 & 120 & 150 & 180 \\
\hline & \multicolumn{8}{|c|}{ Before CPZ treatment } \\
\hline Blood glucose & 84 & 119 & 138 & 134 & 124 & 112 & 113 & 106 \\
\hline $\mathrm{mg} / 100 \mathrm{ml}$ & \pm 4 & \pm 10 & \pm 20 & \pm 16 & \pm 15 & \pm 15 & \pm 21 & \pm 19 \\
\hline Plasma insulin & 9 & 29 & 54 & 53 & 59 & 62 & 62 & 44 \\
\hline \multirow[t]{2}{*}{$\mu \mathrm{U} / \mathrm{ml}$} & \pm 2 & \pm 6 & \pm 8 & \pm 10 & \pm 7 & \pm 16 & \pm 16 & \pm 19 \\
\hline & \multicolumn{8}{|c|}{ After CPZ treatment } \\
\hline Blood glucose & 83 & 114 & 118 & 121 & 114 & 108 & 96 & 98 \\
\hline $\mathrm{mg} / 100 \mathrm{ml}$ & \pm 3 & \pm 4 & \pm 9 & \pm 18 & \pm 10 & \pm 11 & \pm 11 & \pm 9 \\
\hline Plasma insulin & 13 & 48 & 74 & 61 & 55 & 54 & 44 & 41 \\
\hline$\mu \mathrm{U} / \mathrm{ml}$ & \pm 4 & \pm 10 & \pm 19 & \pm 9 & \pm 10 & \pm 7 & \pm 9 & \pm 7 \\
\hline
\end{tabular}

basal glucose utilization rate was $1.78 \pm 0.09$ and after treatment it was $1.76 \pm 0.18$. There is no significant difference between these two results. The insulin response after glucose i. v. did not appear to be modified by administration of CPZ (Table 2).

Chlorpromazine infusion caused a slight but significant increase in blood glucose which was still evident $30 \mathrm{~min}$ after the end of the infusion (Fig. 1). On the other hand, plasma insulin did not change during the infusion and after it the mean plasma insulin was slightly increased, but not significantly so. The insulin/ glucose ratio dropped slightly but not significantly during the infusion, but after it the ratio was significantly increased (Fig. 2).

In patients with chemical diabetes, i. v. glucose injection during a CPZ infusion induced higher blood glucose levels and lower plasma insulin concentrations than in control tests, but the various differences at particular time did not appear to be significant (Table 3 ). On the contrary, the differences between the insulin/glucose ratios during saline and CPZ infusions, after an i. v. glucose load, were statistically significant $(\mathrm{p}<0.01)$.

\section{Discussion}

In the past few years it has been demonstrated repeatedly that $\mathrm{CPZ}$ produces hyperglycaemia and glucose intolerance in laboratory animals and in man (Hiles, 1956; Bhide, Tiwari and Balwani, 1965; Waitzkin, 1966; Mennear and Miya, 1970).

Recently Ammon et al. (1973) have shown that this drug inhibits insulin release from isolated islets of Langerhans in vivo and diminishes insulin secretion in rats. They suggested that the inhibition of insulin release was due to decreased activity in the beta-cells of 


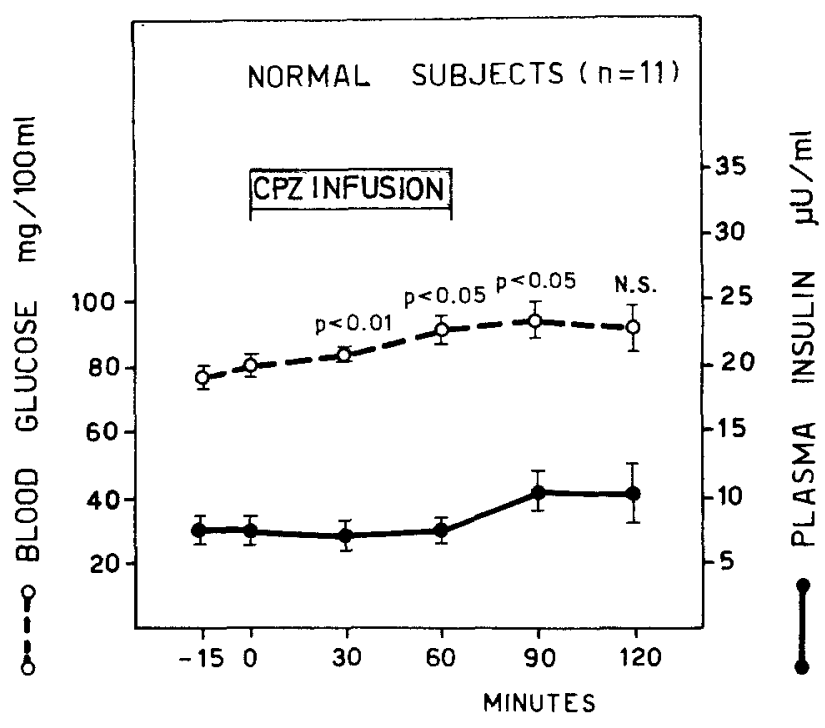

Fig. 1. Changes in blood glucose and plasma insulin during and after CPZ infusion ( $50 \mathrm{mg}$ in $60 \mathrm{~min}$ ) in 11 healthy subjects. Vertical bars denote SEM. N. S. = not significant

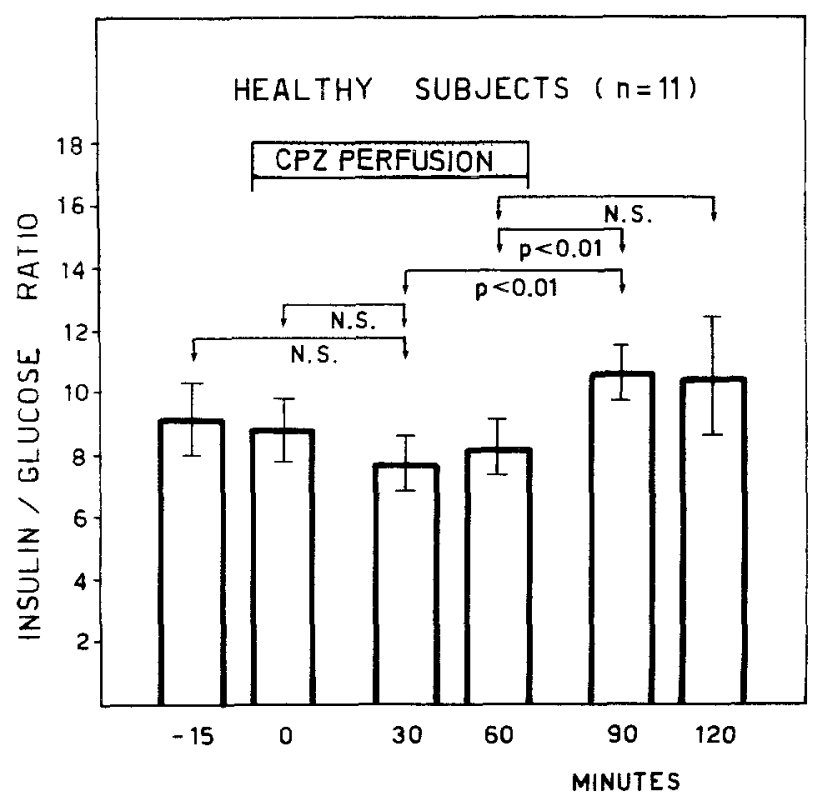

Fig. 2. Changes in insulin/glucose ratio during and after $\mathrm{CPZ}$ infusion (50 mg in $60 \mathrm{~min}$ ) in 11 healthy subjects. Vertical bars denote SEM. N. S. = not significant

Table 2. Effect of short-term CPZ treatment ( $50 \mathrm{mg} /$ day/7 days) on blood glucose and plasma insulin in ten normal subjects after intravenous glucose injection (Mean \pm SEM)

\begin{tabular}{|c|c|c|c|c|c|c|c|c|c|c|}
\hline Time (min) & 0 & 3 & 10 & 20 & 25 & 30 & 35 & 40 & 50 & \\
\hline \multicolumn{11}{|c|}{ Before CPZ treatment } \\
\hline Blood glucose & 68 & 217 & 179 & 143 & 136 & 122 & 104 & 98 & 92 & 86 \\
\hline $\mathrm{mg} / 100 \mathrm{ml}$ & \pm 4 & \pm 10 & \pm 6 & \pm 8 & \pm 10 & \pm 10 & \pm 8 & \pm 7 & \pm 7 & \pm 7 \\
\hline Plasma insulin & 6 & 43 & 25 & 20 & - & 19 & - & 15 & - & 15 \\
\hline$\mu \mathrm{U} / \mathrm{ml}$ & \pm 2 & \pm 7 & \pm 3 & \pm 3 & - & \pm 3 & - & \pm 3 & - & \pm 3 \\
\hline \multicolumn{11}{|c|}{ After CPZ treatment } \\
\hline Blood glucose & 68 & 204 & 182 & 152 & 132 & 129 & 117 & 111 & 102 & 94 \\
\hline $\mathrm{mg} / 100 \mathrm{ml}$ & \pm 4 & \pm 7 & \pm 6 & \pm 7 & \pm 6 & \pm 7 & \pm 7 & \pm 7 & \pm 5 & \pm 7 \\
\hline Plasma insulin & 8 & 48 & 29 & 25 & - & 22 & - & 20 & - & 17 \\
\hline$\mu \mathrm{U} / \mathrm{ml}$ & \pm 1 & \pm 7 & \pm 5 & \pm 4 & - & \pm 3 & - & \pm 3 & - & \pm 3 \\
\hline
\end{tabular}

Table 3. Effect of CPZ infusion on blood glucose and plasma insulin before and after intravenous glucose injection in six subjects with chemical diabetes (Mean $\pm \mathrm{SEM}$ )

\begin{tabular}{|c|c|c|c|c|c|c|c|c|c|c|c|c|c|c|}
\hline Time (min) & 0 & 15 & 30 & & 33 & 40 & 50 & 55 & 60 & 65 & 70 & 80 & 90 & 120 \\
\hline & \multicolumn{14}{|c|}{ Saline infusion } \\
\hline Blood glucose & 95 & 93 & 93 & $\Xi$ & 246 & 222 & 200 & 191 & 182 & 169 & 168 & 154 & 133 & 113 \\
\hline $\mathrm{mg} / 100 \mathrm{ml}$ & \pm 2 & \pm 3 & \pm 3 & $\bar{g}$ & \pm 7 & \pm 16 & \pm 7 & \pm 8 & \pm 7 & \pm 7 & \pm 8 & \pm 6 & \pm 7 & \\
\hline Plasma insulin & 8 & 8 & 7 &.$\stackrel{\mathscr{J}}{\Omega}$ & 22 & - & 21 & - & 19 & - & 18 & 20 & 18 & 18 \\
\hline \multirow[t]{2}{*}{$\mu \mathrm{U} / \mathrm{ml}$} & \pm 1 & \pm 1 & \pm 1 & $\Xi$ & \pm 4 & - & \pm 3 & - & \pm 2 & - & \pm 1 & \pm 3 & \pm 2 & \pm 1 \\
\hline & \multicolumn{14}{|c|}{$\begin{array}{l}\text { CPZ infusion } \\
(50 \mathrm{mg})\end{array}$} \\
\hline Blood glucose & 99 & 105 & 108 & & 293 & 238 & 216 & 193 & 192 & 184 & 182 & 169 & 160 & 127 \\
\hline $\mathrm{mg} / 100 \mathrm{ml}$ & \pm 4 & \pm 3 & \pm 6 & ஜ & \pm 19 & \pm 14 & \pm 8 & \pm 15 & \pm 7 & \pm 9 & \pm 8 & \pm 8 & \pm 7 & \pm 5 \\
\hline Plasma insulin & 8 & 7 & 7 & $\underset{O}{g}$ & 21 & - & 15 & - & 15 & - & 18 & 17 & 16 & 15 \\
\hline$\mu \mathrm{U} / \mathrm{ml}$ & \pm 1 & \pm 1 & \pm 1 & $\overline{0}$ & \pm 4 & - & \pm 3 & - & \pm 3 & - & \pm 3 & \pm 4 & \pm 4 & \pm 3 \\
\hline
\end{tabular}


the pentose-phosphate shunt. Orci et al. (1972) have also reported that CPZ in small doses inhibited emiocytosis, whereas in high doses it increased the number of autophagosomes in pancreatic beta-cells.

The present results show that at the dose employed for short-term treatment CPZ was ineffective in inhibiting basal and glucose-stimulated insulin secretion and that it did not impair oral or intravenous glucose tolerance. Also, and in agreement with the results obtained in dogs by Bhide et al. (1965), shortterm treatment with CPZ did not affect peripheral glucose utilization in normal man.

Acute administration of CPZ increased the blood glucose level in normal man slightly but significantly, both during and after the infusion. This result was in accordance with observations by several investigators (Norman and Hiestand, 1955; Mennear et al., 1970; Ammon et al., 1973). Since CPZ-induced hyperglycaemia did not increase plasma insulin levels, it is conceivable that acute administration of the drug might inhibit insulin release from pancreatic beta-cells in normal man. This hypothesis is supported by the significant increase in the insulin/glucose ratio after CPZ infusion.

In patients with chemical diabetes, $\mathrm{CPZ}$ infusion caused a significant fall in the insulin/glucose ratio after an intravenous glucose load. This result, too, was in agreement with the concept that CPZ inhibits insulin secretion in man.

Many investigators have demonstrated that $\mathrm{CPZ}$ may release catecholamines from the adrenals (Carlson and Hillarp, 1961; Opitz, 1962) and it has been suggested that the hyperglycaemic response to a single dose of CPZ alone is due, at least in part, to stimulation of the adrenals (Bhide et al., 1965; Mennear et al., 1970). Indeed, in some of our patients CPZ infusion caused discomfort, tachycardia and slight hypotension. Therefore the present results cannot exclude the possibility that both the hyperglycaemia and inhibition of insulin release might have been due to increased release of catecholamines.

\section{References}

Ammon, H., Steinke, J.: Apparent biphasic effect of chlorpromazine on insulin release from isolated rat pancreatic islets. Diabetes Suppl. 20, 345 (1971)
Ammon, H., Orci, L., Steinke, J.: Effect of chlorpromazine (CPZ) on insulin release in vivo and in vitro in the rat. J. Pharmacol. exp. Ther. 187, 423-429 (1973)

Bhide, M., Tiwari, N., Balwani, J.: Effect of chlorpromazine on peripheral utilization of glucose. Arch. int. Pharmacodyn. 156, 166-171 (1965)

Carlson, A., Hillarp, N.: Uptake of phenyl and indole alkylamines by the storage granules of the adrenal medulla in vitro. Med. exp. (Basel) 5, 122-124 (1961)

Federspil, G., Casara, D., Stauffacher, W.: Chlorpromazine in the treatment of endogenous organic hyperinsulinism. Diabetologia 10, 189-191 (1974)

Gerich, J., Martin, M., Recant, M.: Clinical and metabolic characteristics of hyperosmolar nonketotic coma. Diabetes $\mathbf{2 0}$, 228-238 (1971)

Herbert, V., Lau, K., Gottlieb, C., Bleicher, B.: Coated charcoal immunoassay of insulin. J. clin. Endocr. 25, 1375-1384 (1965)

Hiles, B.: Hyperglycaemia and glycosuria following chlorpromazine therapy. J. Amer. med. Ass. 162, 1651 (1956)

Hugget, A., Nixon, D.: Use of glucose peroxidase and o-dianisidine in determination of blood and urinary glucose. Lancet $1957 \mathrm{II}$, 368-370

Lambert, A., Henquin, J. C., Orci, L.: Chlorpromazine in malignant insulinoma. Brit. med. J. 1972 III, 701

Mennear, H., Miya, T: Chlorpromazine-induced glucose intolerance in the mouse. Proc. Soc. Exp. Biol. 133, 770-773 (1970)

Norman, D., Hiestand, W. A.: Glycemic effects of chlorpromazine in the mouse, hamster and rat. Proc. Soc. exp. Biol. (N. Y.) 90, 89-91 (1955)

Opitz, K.: Wirkungen psychotroper Substanzen auf den Stoffwechsel. 3. Mitteilung. Arzneimittel-Forsch. 12, 618-626 (1962)

Orci, L., Ammon, H., Steinke, J.: The effect of chlorpromazine on insulin release from isolated pancreatic rat islets: A correlated morphological and biochemical study. Diabetologia 8, (Abstr.) 61 (1972)

Rayfield, E., George, D., Beisel, W.: Altered growth hormone homeostasis during acute bacterial sepsis in the Rhesus monkeys. J. clin. Endocr. 38, 746-754 (1974)

Scandellari, C., Zaccaria, M., Sicolo, N., Casara, D., Erle, G., Federspil G.: Medical treatment of endogenous organic hyperinsulinism. Horm. Metab. Res. Suppl. 6, 46-54 (1976)

Sherman, L., Kim, S., Benjamin, F., Kolodny, D.: Effect of chlorpromazine on serum growth hormone concentrations in man. New Engl. J. Med. 284, 72-74 (1971)

Waitzkin, L. A.: A survey for unknown diabetes in a mental hospital. Diabetes 15, 164-172 (1966)

Received: January 27, 1976, and in revised form: June 14, 1976 , accepted: July 9, 1976

Dr. G. Federspil

Istituto di Semeiotica Medica

dell' Universitá di Padova

Via Ospedale Civile, 105

I-35100 Padova

Italy 